\title{
The Memory-Modifying Potential of Optogenetics and the Need for Neuroethics
}

\author{
Agnieszka K. Adamczyk (D) Przemysław Zawadzki $($ D
}

Received: 21 December 2019/Accepted: 30 September 2020 / Published online: 17 October 2020

(C) The Author(s) 2020

\begin{abstract}
Optogenetics is an invasive neuromodulation technology involving the use of light to control the activity of individual neurons. Even though optogenetics is a relatively new neuromodulation tool whose various implications have not yet been scrutinized, it has already been approved for its first clinical trials in humans. As optogenetics is being intensively investigated in animal models with the aim of developing novel brain stimulation treatments for various neurological and psychiatric disorders, it appears crucial to consider both the opportunities and dangers such therapies may offer. In this review, we focus on the memory-modifying potential of optogenetics, investigating what it is capable of and how it differs from other memory modification technologies (MMTs). We then outline the safety challenges that need to be addressed before optogenetics can be used in humans. Finally, we re-examine crucial neuroethical concerns expressed in regard to other MMTs in the light of optogenetics and address those that appear to be unique to the memory-modifying potential of optogenetic technology.
\end{abstract}

\footnotetext{
A. K. Adamczyk

Institute of Psychology, Jagiellonian University, Krakow, Poland e-mail: a.k.adamczyk@uj.edu.pl

P. Zawadzki $(\bowtie)$

Institute of Philosophy, Jagiellonian University, Krakow, Poland e-mail: przemyslaw.zawadzki@uj.edu.pl
}

Keywords Optogenetics · Memory modification technologies (MMTs) · Memory · Neuroethics · Safety · Moral obligations $\cdot$ Autonomy $\cdot$ Exploitation

\section{What Is Optogenetics?}

Combining genetic engineering with optics, optogenetics enables the user not only to record but also to manipulate the activity of individual neurons in living tissue with the use of light and to observe the effects of such manipulation in real time [1,2]. To this end, neurons of interest are genetically modified to be made responsive to light, which is done by means of inserting opsin genes (genes that express light-sensitive proteins). This is typically achieved with the aid of engineered viruses that are infused into a targeted region of the brain. ${ }^{1}$ To enable the selective expression of light-activated proteins in a particular neural type, a cell-type specific promoter is added to the genetic construct within the vector. Once opsin genes arrive at their determined destination, they cause neurons to express light-sensitive proteins. When illuminated with light, the channels of these proteins regulate the flow of electrically charged ions across membranes, exacerbating or inhibiting the neuron's firing of action potentials, thus facilitating or preventing its communication with other neurons (depending on which light-activated protein is used). Thanks to this procedure, specific neurons can be activated or deactivated "at will,"

\footnotetext{
${ }^{1}$ To learn about methods of neuronal targeting, see Packer et al. [3].
} 
making optogenetics a highly selective and precise technique for manipulating neural activity.

\section{The Need for Further Neuroethical Debate}

Although optogenetics is a relatively new neuromodulation technology, whose various implications are, to a large extent, difficult to foresee at the current stage of research, its therapeutic potential has already prompted approval for the first human trials in the hope of developing novel treatments for intractable diseases, such as blindness. Initial approval was provided in 2015 by the US Food and Drug Administration (FDA) to RetroSense Therapeutics (Ann Arbor, MI, USA $^{2}$ ) and in 2018 by the EU Clinical Trials Directive to GenSight Biologics (Paris, France ${ }^{3}$ ). Both approvals concerned authorization for a phase I/II clinical trial for restoration of vision in people suffering from retinitis pigmentosa [4]. Another disease awaiting the approval of initial clinical trials involving the application of optogenetic therapy and for which existing methods of treatment show limited effectiveness is urinary bladder syndrome [5]. Furthermore, many optogenetic studies conducted on animal models, such as rodents or nonhuman primates [6], were designed with the explicit goal of developing better targeted brain stimulation treatments for various psychiatric and neurological disorders in humans [7-14]. These attempts, along with rapid advancements in the field, demonstrate that optogenetics is already progressing towards clinical application. Moreover, some (e.g., $[9,11,15])$ argue that it could also become an alternative form of therapy to deep brain stimulation (DBS), another form of invasive neuromodulation technology, ${ }^{4}$ which, over the past decade, has become a widely accepted treatment method for patients struggling with different types of disorders. However, it is worth mentioning that both methods seem to be developing in parallel: while some scientists are putting their efforts into refining DBS to gain greater, optogenetic-like precision in targeting specific brain

\footnotetext{
2 https://clinicaltrials.gov/ct2/show/NCT02556736

${ }^{3} \mathrm{https} / / /$ clinicaltrials.gov/ct2/show/NCT03326336

${ }^{4}$ Deep brain stimulation (DBS) is an invasive method involving implantation of electrodes and electrical stimulation of specific regions of the brain $[16,17]$. The American Food and Drug Administration (FDA) approved DBS as a treatment in Parkinson's disease, dystonia, essential tremor, and obsessive-compulsive disorder. Today, the number of patients being treated with DBS is estimated at over 150,000 [18].
}

structures [19], others are trying to "refine" optogenetics to make it less invasive and to enhance its potential as a future treatment [20].

Although approval for the first clinical trials involving optogenetic interventions on human subjects has already stimulated preliminary discussions of most of the basic dilemmas, such as efficacy and safety concerns (which are actually common to all invasive neuromodulation technologies) [21-25], a more focused debate on the ramifications of specific optogenetic brain interventions in humans is still lacking. As such interventions are becoming more and more plausible, given the pace of advancement in this field and the fact that the majority of optogenetic studies are designed exactly for this purpose, we argue that it is crucial to begin to address the ethical challenges that optogenetics may entail. In the context of neuroethics, studies on memory modification with the use of optogenetics constitute a particularly relevant research area. This review aims to demonstrate how recent breakthroughs in memorymodifying research conducted on animal models can inform us about the potential threats and opportunities optogenetics offers. In particular, we will examine what optogenetics is capable of, how it differs from other existing memory-modifying technologies (e.g., DBS, various memory-modifying drugs), and what safety concerns need to be addressed before optogenetics can be used on humans. Finally, we will re-examine crucial neuroethical concerns expressed regarding other MMTs in the light of optogenetics as well as neuroethical challenges unique to the memory-modifying potential of optogenetics.

\section{Optogenetics: New Possibilities}

Optogenetics enables far more precise and selective neural control than any other existing neuromodulation technique. For instance, DBS involves time-specific electrical stimulation of the brain via implanted electrodes. However, electrical currents spread non-selectively, such that fibers in the vicinity of electrodes are activated along with the targeted cells, making it difficult to estimate the actual volume of stimulated tissue [26]. In contrast, pharmacological agents act more selectively, as they bind to specific receptors. However, as they alter neuronal responding for hours following administration of the drug, they lack temporal precision [27]. 
Contrastingly, optogenetics can selectively and bidirectionally modulate (i.e., enhance or inhibit) specific cellular activity on timescales relevant to the temporal dynamic of neural networks [2]. Moreover, since optogenetics uses light pulses instead of electrical currents, it is compatible with neural and electrochemical recording [28], thus enabling the adoption of real-time stimulation parameters based on recorded activity of the brain. These features of optogenetics makes it unsurpassed, in terms of both spatial and temporal accuracy, with respect to already existing MMTs. We will now present some of the optogenetic findings derived from studies on animal models that foreshadow what lies ahead.

\section{Memory Modification with the Use of Optogenetics}

\section{Implantation of "False Memories"/Modification of Memory Details}

As already mentioned, memory-modifying research is one area which can provide a glimpse of the capabilities of optogenetics. The first optogenetic study to gain widespread publicity ${ }^{5}$ was a study by Ramirez et al. [29] in which authors attempted to implant a false memory in a mouse by means of contextual fear conditioning. To this end, they tagged neurons of memoryengram regions of the hippocampus ${ }^{6}$ that were active when the mouse was placed in one context (context A), and then activated them with light when the mouse was placed in a different context (context B), in which it was given mild electric shocks. This procedure produced an association between the memory of the previously neutral context $\mathrm{A}$ and the aversive stimulation received in context $\mathrm{B}$, which, when the mouse was reintroduced into context $\mathrm{A}$, generated a fear response (despite the absence of any further light stimulation). To confirm that researchers did not create a generalized fearful memory response to any context, the mouse was placed in a completely new context, $\mathrm{C}$, where it displayed no fear response, instead freely exploring the new environment. These results were replicated by another research group [30]. Although false memories had previously

\footnotetext{
$\overline{5}$ Two leading authors of this research were invited to give a TED talk: https://www.ted.com/talks/steve_ramirez_and_xu_liu_a_mouse_a laser_beam_a_manipulated_memory?language=en

${ }^{6}$ Regions known to encode a specific memory trace, or memory engrams, which are reactivated upon retrieval.
}

been planted using relatively simple misinformation techniques, i.e., providing misleading information about a past event either to distort the recollection of certain details of an existing memory or to implant a new, completely fabricated memory, this was the first study to implant a "false memory" by manipulating the brain activity of a non-speaking subject, bypassing the need of any form of communication, on which simpler psychological methods rely heavily (see [31]). This optogenetic procedure also has the unique advantage of not relying on human-derived factors that might moderate the rate of success in implanting false memories. For instance, in a classic study that used the "Lost in the Mall" technique, ${ }^{7}$ implantation of false memories of being lost in a shopping mall in childhood [31] was successful in only $\sim 25 \%$ of participants (or even less, see [32]); further studies showed that this success rate might be greatly dependent on the convincingness of the story, the characteristics of those subjected to this procedure (e.g., age and level of suggestibility), and the characteristics of those conveying the story (such as age advantage and family relationship between the implanter of the false memory and the individual who had the memory implanted) (e.g., [33]).

\section{Recovery of "Lost" Memories}

Another impressive demonstration of the potential of optogenetics was provided by research on the recovery of "lost" memories. Autobiographical memories formed in early infancy in both humans and animals (including mice) are rapidly forgotten, a phenomenon known as childhood or infantile amnesia [34]. Until recently, it was unknown whether such memories were permanently erased, e.g., due to storage failure, or became increasingly inaccessible with time, e.g., due to retrieval failure. Initial resolution of this question was provided by Guskjolen et al. [35]. In this study, infant mice were subjected to contextual fear conditioning, creating a memory of having received an electric shock in a particular context (a specific chamber). Although such memories normally decay with time due to infantile amnesia, Guskjolen et al. [35] managed to retrieve these "lost" infant memories by first targeting the

\footnotetext{
${ }^{7}$ The "Lost in the Mall" technique is a memory implantation method developed by Elizabeth Loftus and Jim Coan in order to show the ease with which one can manipulate human memory through suggestions about events that never actually took place.
} 
hippocampal neurons responsible for their original encoding during infancy and then reactivating them 3 months later when the mouse reached adulthood. This finding demonstrated for the first time that infant memories are probably not permanently erased, but rather become inaccessible with time due to retrieval failure. In a similar vein, another research group showed that memories retained under retrograde amnesia which resist retention based on the use of natural recall cues are not completely lost and can be recovered using optogenetic stimulation, once again providing evidence of a failure of retrieval rather than of storage [36, 37]. Both instances are pioneering, as the retrieval of "lost" or inaccessible memories has never been achieved by any other memory-manipulation technique and opens up completely new and exciting avenues for future research. For instance, its application to human subjects may at last verify some psychoanalytic claims which attribute a special role to bringing repressed memories to consciousness in order to integrate them with the subject's representation of the self, with the aim of selftreatment.

Erasure and Recovery of Selected Memories on Demand

Some evidence indicates that optogenetics can also erase and recover selected memories on demand-the capability so desperately sought after by the protagonists of the film Eternal Sunshine of the Spotless Mind (2004), who change their minds about consigning their love affair to oblivion. This extraordinary possibility was demonstrated by Nabavi et al. [38], who were able to repeatedly deactivate and reactivate a specific memory by modifying its synaptic strength. In this study, animals learned to associate optogenetic stimulation (applied to the lateral amygdala) with an aversive shock. Once this memory had been formed-as evidenced by a conditioned freezing response to optogenetic stimulation-researchers exposed the rats to an optical long-term depression (LTD) protocol which disturbed this associative memory - as evidenced by the absence of the freezing response to optogenetic stimulation applied on the following day. To test whether this suppressed memory could be restored, the animals were then exposed to a long-term potentiation (LTP) protocol, which succeeded in recovering the previously deactivated memory - as evidenced by re- establishment of the freezing response to optogenetic stimulation.

Remarkably, another line of research demonstrated that it may be possible to reversibly deactivate and reactivate not only relatively new [38] but even very remote, well-consolidated memories with the use of optogenetics [39]. This was achieved by first training a group of mice to associate an auditory cue with an electric shock (which resulted in the acquisition of an auditory-cued fear memory), and then exposing them to the cue 4 weeks later while inhibiting CA1 hippocampal neurons, which abolished recall of the remote fear memory. Importantly, this interference was shown to be temporary (i.e., reversible): when mice were re-tested on the next day without optogenetic intervention, the fear memory was still present and mice expressed the freezing response to the shock-predicting auditory cue. Heretofore, no other method has yet been able to switch selected memories on and off "at will." Although the erasure of memories has been previously achieved using amnestic agents, which, administered after learning, can prevent the consolidation of newly-acquired memories, these compounds were shown not only to act non-selectively-i.e., impairing memory of all recently encoded events and producing a form of general retrograde amnesia - but also to be toxic for humans, which precludes their (clinical) use [40].

\section{Modification of Memory Valence}

However, for both therapeutic and ethical reasons, erasing memories may not always be desirable. ${ }^{8}$ Thus, some researchers attempted to apply optogenetics to evoke memory valence changes (for instance, by turning a "bad" memory into a "happy" one) without affecting the content of memory (declarative memory of an event). This was achieved for the first time by researchers from the Tonegawa group [41], who demonstrated that upon reactivation of a memory engram (encoded by dentate gyrus cells of the hippocampus), the valence of an elicited conditioned response could be reversed by means of its reassociation with a new unconditioned stimulus of an opposite valence. Although influencing memory valence had been achieved earlier

\footnotetext{
${ }_{8}$ This very important subject matter emerging from the new possibilities created by the potential of optogenetics for memory modification should be carefully examined within the neuroethical community. We take the first step in this process in the final section.
} 
by means of memory-modifying drugs [42], these substances usually act through attenuating memory consolidation, which changes, to some extent, the degree to which the memories being consolidated are remembered.

\section{Modification of Memory (Re)consolidation}

Optogenetics was also demonstrated to modulate memory consolidation, i.e., the process of stabilization of a memory trace following its initial acquisition [43]. For instance, researchers showed that it was possible to facilitate or impair retention of selected new memories by stimulating or inhibiting selected groups of neurons of the amygdala [44]. As mentioned above, modification of consolidation processes can be carried out using memory-modifying drugs such as propranolol or mifepristone, which manipulate the release of stress hormones. Specifically, research shows that emotional events cause an increase in the production of stress hormones, such as adrenaline, norepinephrine, and glucocorticoids, which strengthens memories of such events by enhancing consolidation [45]. For this reason, drugs that mimic or block the release of stress hormones can non-selectively modulate memory for events that are currently being consolidated. These agents were proved to work especially well, reinforcing or impeding the consolidation of an emotional memory, when administered in the immediate aftermath of the emotional event $[42,46]$.

However, as victims typically seek help several weeks after the traumatic event, when memories are well-consolidated, researchers tried to determine whether propranolol could also affect memory reconsolidation, a process during which previously consolidated memories are made labile again via reactivation of the memory trace [47], in order to lessen the symptoms of posttraumatic stress disorder (PTSD). ${ }^{9}$ In a series of three experiments, Wood et al. [48] demonstrated that administration of propranolol (a $\beta$-adrenergic blocker) or mifepristone (a glucocorticoid antagonist) proved ineffective compared with a placebo treatment in blunting PTSD symptoms or affecting physiological response following reactivation of a traumatic memory. These findings were further supported by [49], who also failed

\footnotetext{
${ }^{9}$ PTSD is a debilitating condition characterized by intrusive and persistent recollections of highly emotional memories (Daskalakis \& Yehuda, 2014).
}

to observe propranolol-induced suppression of a retrieved memory in humans. However, it is worth noting that propranolol was shown to be effective in reducing PTSD symptoms [50] or fear-related responses [51] when administered prior to memory reactivation. The initial 1-year follow-up study showed that propranolol could also be effective in treating anxiety disorders and phobias, as patients who received treatment for arachnophobia showed no relapse [52]. However, propranololbased interventions may cause development of maladaptive dispositions in patients; e.g., some patients wanted to pick up a tarantula or let it crawl up their arm, thus doing things that many nonphobic individuals would refuse to do [53]. Furthermore, some researchers argue that the effectiveness of propranolol might be ascribed to disturbed memory retrieval or new facilitated learning [54].

Amnestic agents have also been used to interfere with memory reconsolidation. For instance, it was shown that infusion of a protein synthesis inhibitor [40] or application of electroconvulsive shocks [55] following memory retrieval might be successful in disrupting subsequent memory retention. However, as mentioned earlier, such treatments were shown not only to be too dangerous to be used in humans, but also to produce general retrograde amnesia (i.e., disruption of all encoded memories) rather than specific memory changes (ibidem).

In contrast to amnestic treatment, alteration of the content of specific memories upon their retrieval has been successfully and safely induced using much simpler behavioral methods, such as extinction training or memory updating [56]; for an extensive overview of different behavioral methods of inducing reconsolidation in humans, see [57]. Extinction training - a laboratory model for exposure therapy - is also used to treat patients suffering from anxiety disorder. This therapy is based on repeated exposure to cues or situations evoking fear in patients in order to reduce this emotion as well as to replace a fear-related memory with a new extinction memory. A major limitation of this approach is that its effects are not permanent; when a fear-related memory begins to dominate over the extinction memory, the fear may quickly return $[58,59]$. Contrastingly, behavioral memory updating, which is a type of extinction paradigm, has the distinct advantage of updating a fearrelated memory with non-fearful information introduced upon memory retrieval within the reconsolidation window. Thanks to this procedure, new information is incorporated into an old memory, which is thus updated. Although as of now this approach seems to be the most 
promising type of therapy for affective disorders, it is susceptible to spontaneous recovery/relapse, as shown by several independent attempts to translate laboratory findings into clinical practice [54]. The potential advantage of using optogenetics or optogenetic-like technology for this purpose would be its ability to instantaneously suppress the neural activity responsible for reactivating an unwanted memory at the moment it occurs.

\section{Memory Enhancement}

Optogenetic modifications were also demonstrated to enhance well-consolidated memories of positive experiences, through reactivation of the dentate gyrus engram cells responsible for encoding them originally [60]; importantly, reactivating positive experiences reduced stress-induced behaviors, counteracting deficits in motivation, abnormal responses to behavioral challenges, and anhedonia (reduced ability to seek and experience pleasure) when investigated in an animal model of depression (ibidem). Memory enhancement is being sought today through a vast array of different methods aimed at offering such benefits, ranging from physical exercises and yoga to psychostimulants (e.g., methylphenidate) and invasive neuromodulation techniques (for an extensive review, see [61]). None of them, however, is capable of influencing memory processes in a manner as precise and selective as that of optogenetics. Moreover, even methods that bear the closest resemblance to optogenetics - such as DBS, which inhibits or exacerbates neural activity of selected brain regions via an implanted electrode - appear to possess certain inherent limitations. For instance, stimulation of the hippocampal neurons, although successful in inducing specific memory changes via optogenetics, caused the disruption of memory processes when less precise and selective electrical currents were applied via DBS [62].

Treating Memory Impairment

Last but not least, optogenetic intervention has been recently tested as a potential treatment for various models of neurological disorders tested in animals. The latest evidence indicates that optogenetics, similar to DBS [63], shows potential for improving memory impairments observed in neurological conditions such as diencephalic amnesia and Alzheimer's disease through stimulating small thalamic nuclei [7]. Optogenetics has also contributed significantly to an improved understanding of the dysfunctional neural circuits underlying PTSD [64] and Parkinson's disease [65], inspiring novel circuit-inspired applications of DBS (ibidem). Here, again, the precision of optogenetics may prove to be crucial in obtaining the most desirable outcomes from applied treatment.

\section{Potential Applications of Optogenetics in Humans}

To study optogenetic memory modifications, most of the above-mentioned studies used very simple contextual fear conditioning procedures. Thus, the question arises whether such findings can be translated to humans. Obviously, the answer to this question is far from simple. However, the aforementioned procedure of contextual-fear conditioning relies on an associative memory system common to all mammals, including humans [66]. Moreover, similar procedures have been used to study the impact of other memory-modifying techniques (such as pharmacological agents) on humans (for a review see, e.g., [53]). Thus, at least some degree of translatability (as well as comparability with other MMTs) can be cautiously assumed.

The manipulation of memory in a highly controlled manner, enabling erasure, recovery, enhancement, or implantation of specific memories, holds promise for victims of traumatic events, such as military conflict, terrorism, assault, car accidents, and natural disasters, who might otherwise suffer from intense, painful memories, and who, in many cases, eventually develop PTSD. Although propranolol offers tempering of the emotionality associated with memories, optogenetics may offer a much wider range of possibilities, from the reversible erasure of a disturbing memory [38] or the modification of certain details [29] to the alteration of the memory valence [41], which might facilitate a change in attitude towards the subject's life choices and future.

Moreover, optogenetically based memory intervention - when combined with other therapeutic measures - may also benefit depression patients by reactivating their positive memories and/or tempering negative ones [60]. This speculation is supported by an observation that repeated reactivation of positive memories has been shown not only to ameliorate stressinduced behaviors but also to boost neurogenesis (the production of new nerve cells) [60], counteracting depression-related impairments, such as shrinkage of the prefrontal cortex and hippocampus [67, 68]. Finally, 
it may free patients from prolonged intake of medications and from their undesirable side effects. By influencing consolidation processes, optogenetics may also help to counteract the decay of our most happy memories, enabling us to relive them in full detail, potentially to the end of our lives [44].

By affording access to forgotten memories of infancy, optogenetics could also shed light on a part of our life that had seemed inevitably lost [35]. Some related evidence suggests that optogenetically induced memory modulations could be used even for such trivial purposes as shaping people's preferences and behavior, for instance, by promoting more healthy food choices [69]. More importantly, however, optogenetics promises to restore memory to millions of people who have been deprived of it due to brain injuries or neurodegenerative disorders $[7,64,65]$.

These prospects have made optogenetics one of the most rapidly developing neuromodulation technologies, with an exponential growth in the number of papers containing the word optogenetics in their titles [70]. However, before optogenetics can be used in humans, it will have to face several challenges, which we will now address.

\section{Safety Issues and Technical Challenges}

As with any invasive neuromodulation technology, the most urgent issue requiring consideration is safety. Almost all available treatments for neurological or psychiatric disorders entail some risks and side effects. For an intervention to be authorized for general use, the benefits must outweigh the potential risks. However, predicting the adverse consequences of various technologies is not always easy. A tragic example of a poorly predicted outcome of medical intervention is the case of Jesse Gelsinger, an 18-year-old who died due to multiorgan system failure in the aftermath of clinical trial testing for gene therapy, which, similar to optogenetics, involved the injection of corrective genes inserted into a weakened flu virus that was supposed to evoke only transient, flu-like symptoms [71]. However, since this incident, gene-therapy-based interventions have been significantly improved and apparently no similar accidents have occurred. Despite some inherent risks associated with the infusion of viruses into the human brain, recent studies have demonstrated that the types of vectors used for optogenetic stimulation (i.e., lentiviruses (LVs) or adeno-associated viruses (AAVs)) are generally safe and well tolerated by patients $[72,73]$.

Another challenge that optogenetics will have to face concerns the duration and consequences of the expression of light-sensitive proteins in the human brain. For any gene therapy-based intervention to be successful, the expression of key proteins must persist in neural tissue either for the patient's expected lifespan, or at least long enough to deliver the expected treatment outcome. Although we know that induced expression of non-native proteins remains high in a primate brain for as long as 15 years following the injection of an AAV [74], still more research is needed to determine its exact duration. In addition, there is a need to test the consequences of long-term expression of exogenous proteins in the mammalian brain, which have been studied very little to date.

Another issue that may pose a challenge is the need for rescaling. Present optogenetic studies use mouse brains as a proxy for studying the functioning of the human brain. However, a mouse brain is several times smaller than a human brain, and optogenetic tools will arguably need some adjustments. In particular, vector delivery systems, aimed at producing protein expression in areas large enough to induce observable effects in the human brain, will presumably need to be developed. Furthermore, to stimulate a targeted brain region efficiently, an implantable optogenetic device requires a sufficient light spread and intensity range and must be able to generate diverse illumination patterns (e.g., continuous illumination or short light pulses of changeable frequencies) and wavelengths suitable for activation of the targeted photosensory proteins of interest. ${ }^{10}$ Until recently, neuronal illumination and recording of a neuron's evoked electrical signal required the insertion of two relatively large devices into the brain: fiber optic probes and so-called "optrodes" (fiber optics combined with electrodes). This procedure was highly invasive and characterized by increased tissue damage and declining optical output over time. In order to overcome these limitations, several labs have worked on the development of alternative methods of optogenetic stimulation. Not surprisingly, given the rapid advancement of optogenetic-related technology, they have already proposed several ultra-miniaturized $\left(\sim 20 \mathrm{mg},<10 \mathrm{~mm}^{3}\right)$, fully implantable, battery-free, wireless illumination

\footnotetext{
${ }^{10}$ For the latest proposal for a solution to this problem, see Chen et al. [20].
} 
devices suitable for brain and spinal cord stimulation ([75] for review; [76, 77]).

Optogenetics will evidently have to face another type of challenge of a biological nature. It is highly unlikely that an optogenetically identified set of hippocampal neurons believed to encode a specific memory that researchers may attempt to modify, serves only this single function. Therefore, interventions targeting specific memories may result in unforeseeable side effects. For instance, in one study, strengthening taste-aversion memory in rats resulted in changes in other taste-related behaviors [78]; in another study, boosting of memory abilities was accomplished at the expense of greater sensitivity to pain [79]. Although both of these examples come from studies that employed the molecular form of memory modification, it can be assumed that they may also apply to optogenetics. Some insights into potential and unexpected side effects can be also gained from reports from DBS patients who experienced changes in their behavior, personalities, and identities due to neuromodulation treatment [80-84].

Moreover, the episodic memory system was demonstrated to be widely distributed throughout the brain, comprising not only the hippocampus but also other surrounding structures of the medial temporal lobe, such as the perirhinal, entorhinal, and parahippocampal cortices, as well as sites to which the hippocampus is structurally connected, such as mamillary bodies, thalamic nuclei, or the retrosplenial cortex [85]. Furthermore, creation of emotional memories engages additional brain regions such as the amygdala [86] and prefrontal cortex [87]. Thus, stimulating the selected ensemble of hippocampal neurons may fail to "turn off" a memory one may wish to edit, overwrite, or erase. In these circumstances, it would be necessary to target neurons of the whole network, which seems not only infeasible, but also potentially dangerous (for the reasons we have outlined above). On the other hand, activation of the dentate gyrus neurons that code for contextual content of memory (so often targeted in the aforementioned studies) may prove crucial in initiating the activity of the whole network. This was actually suggested by a study by Goshen et al. [39], who showed that even the recall of very remote, well-consolidated memories stored in the prefrontal cortex required undisturbed activity of the hippocampus (see "Erasure and Recovery of Selected Memories on Demand"). However, this issue will probably not be settled until speaking subjects undergo memory-modifying procedures with the use of optogenetics.

Finally, some of the side effects are difficult to anticipate based on animal models alone, due to the inaccessibility of animals' "subjective thoughts and experiences." Altering memories may yield changes in emotional processes, sense of self, or behaviors. Strikingly, some of these side effects might be undetectable even by future human participants, given that people display an incredible propensity to rationalize their most extraordinary behaviors, as demonstrated indisputably by years of studies on patients subjected to the procedures of implementation of false memories $[31,88]$ or those with commissurotomy or split brain [89]. Thus, unless the change is extreme enough to be visible to others, alterations in a patient's behavior, emotionality, or personality may go unnoticed by the patient himself. This issue is particularly relevant in the context of the unsurpassed precision and selectivity of action of optogenetics.

\section{Call for a Debate on the Neuroethical Consequences of the Memory-Modifying Potential of Optogenetics}

The properties of optogenetics discussed above make it a powerful yet highly ambivalent (in ethical terms) neuromodulation technique. Moreover, as optogenetics is one of the fastest-developing neuromodulation technologies, with more and more laboratories becoming equipped with optogenetic tools worldwide, and as it differs from previous MMTs, there is an urgent need to initiate a debate on its more elusive ethical consequences before it can be allowed as an accepted form of treatment for humans.

This review is a first step in this process, as we considered new emerging possibilities associated with optogenetics in the field of memory modification, and contrasted it with other MMTs to shed light on differences distinguishing these techniques. Moreover, we analyzed the most general challenges that optogenetics will have to face before it can be applied as a form of treatment or cognitive enhancement in humans. Some of the most basic ethical issues (such as efficacy and safety concerns) associated with the application of optogenetics to humans have already begun to be addressed [21-25]. However, as optogenetics is being intensively investigated in the context of the development of effective brain stimulation treatments for various neurological and psychiatric disorders such as 
depression [8], schizophrenia [10, 13], anxiety and pain [11], movement disorders [14], including Parkinson's disease [9, 65], addictions [90], epilepsy [91], and memory-related disorders such as PTSD [12], diencephalic amnesia, and Alzheimer's disease [7], it is conceivable that optogenetics or other optogenetic-like neurostimulation methods (that allow for a similar degree of neural specificity and precision, will eventually be used to apply these findings as a form of therapy in humans. And, indeed, some optogenetics findings regarding characterization of neural circuits and their dysfunction in various brain diseases are currently inspiring novel stimulation protocols that are planned to be applied as a form of treatment in humans by means of refined DBS [92].

Although some dissenting voices have indicated that it is too early yet to consider neuroethical issues which revolve around approaching neuromodulation technologies (see, for instance, [93]), we (as well as some others; see, e.g., $[25,94]$ ) hold opposing views: we believe that the role of neuroethics is actually to think ahead and act proactively rather than reactively, so that a sufficient amount of relevant literature will be available to fall back on when various technologies are about to be applied in humans; in this way, ethics committees will not be forced to make ill-informed ad-hoc decisions when facing the dilemma of whether to issue approval for a specific investigation or treatment involving invasive neurostimulation technologies. Therefore, in the final two sections, we would like to outline some of these more intangible neuroethical challenges. We will consider, in the first section, ethical problems associated with forms of memory modification shared by optogenetics with other MMTs (but which may still generate novel ethical problems), as well as, in the final section, those that may be specific to optogenetics due to its unique memory-modifying possibilities.

\section{Memory-Modifying Potential and Related Neuroethical Challenges of Optogenetics Shared with Other MMTs}

Optogenetics offers some forms of memory modification that have been achieved with the use of other MMTs (albeit, as we mentioned earlier, with varying success and to a limited extent). These include modification of certain details of a specific memory/ implantation of false memories [29, 30] and alteration/diminution of the memory valence [41]. In the following section, we discuss what neuroethical consequences these memory-modifying possibilities can have by revisiting neuroethical challenges that were previously raised towards other MMTs in the light of the memory-modifying potential of optogenetics. In "The Issue of Exploitation," "The Issue of Appropriate Moral Reaction," and "The Issue of Altering Evaluative Schemes and Dispositions," we also present a new context in which memorymodifying potential of MMTs (including optogenetics) can be used and new neuroethical challenges that emerge from these scenarios. More specifically, we argue that modification of valence of soldiers' war memories can lead to several issues: exploitation of soldiers' memories which can be in the interest of authoritarian governments (see "The Issue of Exploitation"), inappropriate moral reactions which may alienate a soldier from society as his/her reactions appear inhuman to third-parties (see, 8.3), and changing evaluative scheme and dispositions which may make soldiers an existential threat to others (see "The Issue of Altering Evaluative Schemes and Dispositions"). Moreover, when discussing these issues in "The Issue of Appropriate Moral Reaction" and "The Issue of Altering Evaluative Schemes and Dispositions" as well as the issue of adaptiveness in "The Issue of Adaptiveness," we indicate when and why novel memory-modifying potential of optogenetics can yield more serious neuroethical consequences compared with the previous MMTs.

The Issue of "Natural" Recovery from Traumatic Experiences

One basic ethical concern associated with medical interventions is the question of who should receive the treatment. As long as prognostic indicators of the development of psychological disorders such as PTSD in the immediate aftermath of trauma are not fully developed, MMTs that rely on intervention within the consolidation window take the risk that the patient will be deprived of the opportunity to attempt recovery from trauma on his or her own through an appeal to rational capacities, for example via the construction of a redemptive story to promote posttraumatic growth [95]. ${ }^{11}$ On the other

\footnotetext{
11 "The experience of positive change that occurs as a result of the struggle with highly challenging life crises" [96].
} 
hand, as some MMTs (e.g., propranolol, optogenetics) have the potential to modify even well-consolidated memories, this opportunity may reduce the above ethical concern through the introduction of legal regulations mandating that only memories contributing to the development of a particular trauma are to be treated (see also [53]).

\section{The Issue of Exploitation}

One fundamental and inherent issue common to all of the interventions discussed above is that memories constituting the most plausible candidates for such modifications often involve some form of moral transgression, as experiences of this kind are especially disturbing and traumatic for humans. However, alteration of the valence of memories involving moral transgression (i.e., switching them from negative to positive) may be ambivalent even in cases where memories have proved to be maladaptive and have resulted in the development of a psychological disorder. Consider the potential usage of MMT to alter the valence of memories of war veterans who have developed PTSD. A government which pursues an imperialist policy may actually possess a vital interest in the modification of the valence of soldiers' war memories not only in order to treat these soldiers but also to use their testimony to propagate more positive images of war in order to gain broader support for military campaigns as well as to gain new recruits attracted by military stories.

\section{The Issue of Appropriate Moral Reaction}

The discussed case, however, entails not only the potential malpractices of authoritarian governments but also the issue of appropriate moral reaction. As moral agents, we can respond to events in more or less appropriate ways $[97,98]$. In the case discussed above, soldiers may have either harmed others or been harmed themselves. Some argue that it is appropriate to feel resentment and indignation in the case of experiencing harm and guilt and regret after harming others [97, 99, 100]. Arguably, if soldiers experienced harm and developed PTSD as the result of an event, the issue of appropriate moral reaction would be less problematic, provided the government did not use the soldiers as a propaganda tool.

However, cases in which soldiers harm others are particularly morally problematic. It may be argued that it would be at least morally ambivalent to modify memories of soldiers who had committed horrific acts, even if those memories resulted in PTSD. Consider the consequences of altering the valence of the dreadful memories of a soldier who had committed genocide, who would thus arguably be free from PTSD along with the guilty conscience that would normally have resulted from his deeds. Some would argue that murderers should express appropriate moral reactions to deeds they have every reason to feel guilty about. ${ }^{12}$

Even more morally alarming in this case is that the valence of the soldier's memory of genocide would be changed from negative to positive- the opportunity provided by the novel potential of optogenetics. Thus, he might actually develop a disposition to take pleasure in recalling his inhuman acts. This situation seems entirely different, from a moral standpoint, from one in which the valence of a traumatic memory is merely blunted (as is already offered by MM drugs, such as propranolol). It might be argued that every human being - independently of his or her past - deserves to be free from psychological disorders or even from a guilty conscience; however, it is much more controversial to argue that humans have the right to alter the valence of memories of their own horrific acts so as to actively enjoy them.

The Issue of Altering Evaluative Schemes and Dispositions

Moreover, assuming that alteration of the valence of a particular memory could become generalized to other instances of this type of memory (e.g., from a memory of killing a particular person to memories of killing other people), it might introduce changes in an individual's overall evaluative system of such acts as well as in his desires. For instance, a soldier, having changed the valence of his war memories, could develop "a taste for killing." Thus, meddling with the valence of traumatic memories of war veterans could make them "sociopathic," as they might become disposed to obtain satisfaction from harming others - the possibility that seems to be especially acute in case of optogenetic interventions involving the change of valence from negative to positive.

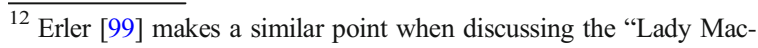
beth" case presented in Kass [101].
} 
The Issue of Authenticity

The possibility that blunting memories may change the evaluative system of a person is linked to the issue of authenticity. In many conceptions of authenticity, deriving from various lineages - essentialist (self-discovery) (e.g., [102]), existentialist (self-creation) (e.g., [103] [1943]), and dual-basis framework (e.g., [104]) — being "truthful" to oneself is directly associated with living in alignment with one's values. Thus, a person whose values have been changed as a result of alteration of the valence of her memories would commit either an act of "betrayal" of her true self, according to the essentialists, since, as a result of her evaluative change, she might begin to lead a life inconsistent with her given and fixed essence (for further considerations, see [105]), or an act of self-deception, according to the "Sartrean" existentialists, as the process of self-creation would stem not from the values that she had freely chosen, but from those constituting side effects of the memory-modifying intervention (for additional considerations see, [99, 106]). Either way, such an intervention may pose a threat to the patient's authenticity.

The Issue of Adaptiveness

Another problem with the kinds of memorymodifications common to various MMTs is that some memories, despite being unequivocally negative or disturbing, may be highly adaptive; accordingly, changing the valence of certain highly aversive and unpleasant memories may be undesirable or even dangerous in cases where the memory is indicative of a genuine threat. Let us recall the above-mentioned consequences of propranolol-based interventions in cases of arachnophobia, in which participants developed generalized and excessively positive responses to spiders - a disposition which could prove deadly in an encounter with a venomous spider in the wild [53]. As optogenetics potentially offers not only to blunt the emotionality of specific memories and associated emotional reactions - as in the case of propranolol-but also to switch the valence of specific memory, the issue of adaptiveness could become even more problematic when memory-modifying interventions are applied with the use of optogenetics.

Elsey and Kindt [53] also point out that interventions that resulted in "the development of an overly potent appetitive memory could be highly disruptive. This is evident in addiction, in which the rewarding properties of drug consumption gave so much control over behavior that the drug is pursued even to the detriment of the person's health, relationships, and personal commitments." Therefore, going "beyond the norm" regarding the emotional valence of a given memory may prove unfavorable, whether the change of valence is from positive to negative or vice versa.

\section{Unique Memory-Modifying Potential of Optogenetics and Related Neuroethical Challenges}

On the other hand, optogenetics offers unique possibilities that have never been achieved with the use of any other MMT. In "The Issue of Losing Motivation to Work for Systemic Change," "The Issue of Negative Composition Effects," and "The Issue of Autonomy and the Principle of Conformity Regarding Memory Erasure," we revisit some of the neuroethical challenges that have been raised towards hypothetical memorymodifying interventions before the advent of an MMT that could actually enable them. As now optogenetics can be regarded as such anticipated MMT, we revise these arguments in the light of optogenetics findings, grounding prior speculations in the empirical reality. Moreover, optogenetics provides even greater memory-modifying opportunities than have previously been assumed including selective and reversible erasure (repeated deactivation and reactivation) of a specific memory and the retrieval of forgotten (or suppressed) memories. These new possibilities for memory modification may be associated with novel neuroethical challenges that have not previously been addressed. Thus, in the final sections "The Issue of Moral Obligations" and "The Issue of Personal Identity," we discuss some new neuroethical challenges that could arise due to unique memory-modifying prospects of optogenetics and propose a new solution to one of the previously speculative concerns.

The Issue of Losing Motivation to Work for Systemic Change

The nature of the human mind is such that often the most plausible target of optogenetic erasure comprises traumatic yet self-defining memories, since traumas often play a critical role in forming personal identity [95, 107]. Furthermore, traumatic memories may also play 
a role in shaping the personality; for instance, those who experienced childhood trauma were shown to exhibit greater empathy than those who did not [108]. Finally, as demonstrated by the \#MeToo movement or, recently, by the \#BlackLivesMatter movement, some intersubjectively shared types of traumatic experiences and memories (such as of sexual abuse or racial discrimination) may, for instance, motivate people to organize in order to combat systemic forms of maltreatment that they and those close to them have experienced. Thus, removing traumatic memories may render systemic change in society impossible: people freed from traumatic experiences might lose the motivational component of their traumatic memories and cease to fight against the injustices they have experienced.

\section{The Issue of Negative Composition Effects}

It can be argued, nonetheless, that people should not be forced to retain their traumatic memories, as a human being should be treated not as a means for other ends (here, the welfare of society), but rather as an end in itself. However, as Lavazza [109] points out, the combination of several individual choices can entail negative composition effects. In a nutshell, although each individual does what appears, prima facie, to be the best for herself - e.g., erase memories of maltreatment — and enjoy temporarily subjective relief from painful experience, in the absence of centralized coordination of these actions, individual choices may backfire on both the individual making them as well as, in the future, other members of society, as the objective conditions that led to the traumas in the first place remain unchanged; thus, the aggregate consequences of the choice to erase traumatic memories made by a sufficient number of individuals would actually help to preserve oppressive social relations and serve the interests of oppressors.

Negative composition effects need not appear at the level of society; they may also be revealed at the more "local" level of the life of an individual. A hypothetical case posed by Glannon [110] is a good exemplification of this: a young academic experiences a traumatic failure during a public event; devastated, she decides to erase the memory of this event. However, similar failures happen again and again. On every occasion, she uses optogenetics to erase the disturbing memory. Thus, as the opportunity to erase memories is always available to the young scholar, she avoids dealing with the structural weakness responsible for her failures.
Consequently, she falls into a cycle of repeating mistakes and erasing her memories of them. Thus, although subjectively well, she will eventually be overwhelmed by external reality, ending up worse off than she would have been without optogenetic interventions. ${ }^{13}$

The Issue of Autonomy and the Principle of Conformity Regarding Memory Erasure

Not allowing for dampening traumatic memories on the above discussed grounds - due to concerns about negative composition effects - may breach not only the Kantian imperative, but also the liberal principle of individual autonomy understood as "self-rule" or "selfgovernment" [113]. According to the latter principle, the very idea of self-rule relies on the right to control one's own mind; thus memories - being a fundamental part of it - would certainly seem to be included (see [114]). However, given the nature of life in society, it is apparently beneficial for all parties to impose certain limitations on the potential choices and actions of its members; here, for example, Mill's principle of liberty might be recalled. ${ }^{14}$ Moreover, in an apparent paradox, imposing restrictions on personal autonomy can be beneficial in terms of exercising autonomy: a Hobbesian society functioning according to the homo homini lupus rule would possibly exercise autonomy at the beginning (at least of some of the most powerful members of society), but over time "continuous conflict would repeatedly put at risk our ability to self-determination, since violent interferences with our choices would be the norm. It therefore seems that the "rule" of autonomy should be implemented so that, even if everyone took it to the highest degree, it would still be possible for everyone to exercise it" [109].

We are not arguing that an individual's interest in avoiding pain from traumatic memories and potential development of PTSD should be always subordinate to society's interest in changing oppressive structures. Potential middle-ground pragmatic solutions exist. Lavazza [109] proposed, for instance: "to allow the treatment to those who show the greatest signs of suffering." At the same time, we may want to ask the most motivated individuals to be "volunteers" and to preserve

\footnotetext{
$\overline{{ }^{13} \text { See Lavazza }}[111,112]$, who considers this case in terms of the risk of losing touch with reality and the consequences thereof.

14 “... that the only purpose for which power can be rightfully exercised over any member of a civilized community, against his will, is to prevent harm to others" [115].
} 
their memories intact in order to continue the fight against experienced injustices. Moreover, it is worth noting that, as long as choices to erase memories arise only occasionally, the principle of autonomy appears to outweigh the principle of conformity regarding memory erasure mentioned above.

In our view, however, there will always be a tension between the interests of the individual and society, as it is unlikely that governments (or other decision-makers) will ever be able to reliably predict the aggregate consequences emerging from the decisions of individuals. Thus, assessment of the admissibility of optogenetic memory modifications is no simple matter, as it requires careful consideration of the aggregate societal consequences of these interventions.

\section{The Issue of Moral Obligations}

Kolber [114] considers a situation in which a bystander is the only person to see the face of a serial rapist fleeing the home of his latest victim. Arguably, most would agree that even though this bystander might find this memory upsetting and might want to erase it, she should be legally obliged to retain it in the interests of preventing the serial rapist from committing future crimes. This case raises the issue of moral obligations regarding memory modifications. However, should we reach the same conclusion when the only person to see the serial rapist's face is the victim of the rape? When Kolber posed this question in 2006, the only way to diminish a given memory was through interference with the process of its formation. Therefore, the decision whether to dampen a memory had to be made quickly, within several hours after the event in question, which would preclude the victim's testimony in a subsequent court trial. Postponing memory erasure, on the other hand, would render the procedure ineffective. In an attempt to answer the above question, we may again consider negative composition effects: if every victim erased her traumatic memory, social safety would deteriorate greatly, since no victims would testify and criminals would remain free to commit additional crimes [109]. However, given the novel capacity of optogenetics to target and selectively erase wellconsolidated memories, we may possess tools in the future to erase traumatic memories after their deposition within the context of a criminal prosecution; thus, this protocol could provide a solution to the discussed problem. Moreover, speculatively, in a case where such memories were desperately needed during other stages of the prosecution (as arguably might sometimes be the case), optogenetics could potentially reintroduce them into the victim's memory system in order to gain additional necessary evidence. Our considerations here demonstrate that confronting existing arguments with empirical data is crucial as answers to neuroethical problems can differ given distinct capabilities of various technologies.

The moral obligation to remember can be discussed either when one experienced harm (one is the victim), or when one harms others (one is the offender). Liao and Sandberg [97] argue that in a case in which one is the offender, one has "a duty not to remove these kinds of memories until one has come to realize one's errors." Thus, Liao and Sandberg argue for "the duty to remember" on the grounds of the value of the appropriateness of moral reactions. On the other hand, they also emphasize that the moral obligation to remember is particularly relevant if deliberately forgetting might increase the likelihood of future crimes of this type. However, this solution might be questioned, as Liao and Sandberg acknowledge, citing Levy [116], who argues that "deliberate forgetting could decrease the likelihood of future crimes of this type, because remembering may make it easier to commit the crime in the future, since one has already done it before" [97].

Thus - from the perspective of the interests of society and for consequentialist reasons - which of these strategies would be more beneficial in terms of crime prevention is an empirical question. Obviously, however, one can argue in favor of the duty not to erase offenders' memories of moral transgressions on the grounds of other moral values, such as autonomy. Let us recall the protagonist Alex in Stanley Kubrick's A Clockwork Orange (1971), who was "rehabilitated" by means of the aversion therapy to the extent that, as Cabrera and Elger [117] point out, he ceased to be capable of any moral action.

The Issue of Personal Identity

Although it appears that the reversible erasure of a specific memory offers an ideal form of memory manipulation (as we can always bring the erased memory back), there is the risk that the restoration of an erased memory may not be accomplished without consequences. Studies show that some memories may exert enormous impacts on who we are and what we pursue in 
our lives. These are so-called self-defining memories [118]. Singer et al. [119] argue that such memories serve as the ingredients for an individual's overall life story, and thus constitute that individual's narrative identity. Schechtman [120] famously argues that the narrative is the answer to the "characterization question" - the question of "what makes a person who she is." Schechtman also imposes normative constraints upon a narrative considered constitutive of the self. According to the articulation constraint, the narrative must be coherent and intelligible. According to the reality constraint, it must correspond to basic facts about the person's life ([120], 83; 113-114). Thus, in the light of Schechtman's theory of narrative identity and the above insights concerning self-defining memories, the concern regarding optogenetic erasure of a self-defining memory is that a given individual's narrative - the very requirement of being oneself - might be disrupted. ${ }^{15}$

If this were the case, however, it could be argued that, given the capacity of optogenetics to reintroduce memories into the memory system, these potentially undesirable effects of memory erasure/deactivation could easily be reversed through reactivation of the memory trace. However, reactivation of self-defining memories may fail, as the individual's narrative identity may have already changed. Therefore, the individual might feel alienated from the newly reactivated memory as a result of feeling that she is no longer the same person. ${ }^{16}$ Consequently, the re-integration of (previously) selfdefining memories with a subject's newly developed narrative identity might prove impossible.

\section{Conclusions}

Taking the above considerations into account, it appears that optogenetics is not free of the ethical challenges posed by existing MMTs. However, depending on

\footnotetext{
${ }^{15}$ See also a discussion on how a narrative can be endangered by another neuromodulation technology, DBS, as a side effect of memory-unrelated intervention, in Schechtman [121] and Baylis [122]. ${ }^{16}$ Despite the fact that these studies were not associated with interventions in memory, psychological phenomena of alienation were observed as a side effect of neuromodulatory therapy in patients treated with DBS (see, e.g., $[123,124])$. Although optogenetics can be expected to deliver stimulation in a far more precise and selective manner than DBS, it could still lead to some form of psychological alienation that would, however, result not from technological limitations (e.g., imprecise and diffused DBS electrical currents), but from the very act of tampering with a specific memory that could be constitutive for one's personal identity and authenticity.
}

which of the presented methods of memory modification is utilized in practice, these challenges may take different forms.

For instance, as we discussed above, optogenetic interventions promise not only to blunt emotional (traumatic) memories but also to change their valences from negative to positive and vice versa. In cases of such interventions, the issue of exploitation seems to be of particular importance, as political regimes could use optogenetics for their own purposes. On one hand, this concern appears graver in the case of changing a memory's valence, as opposed to erasure of a specific memory, as authoritarian governments may wish to use war veterans as propaganda tools by imposing positive valences on extremely negative, traumatic war memories. On the other hand, the issue of exploitation may prove even more disturbing in cases where optogenetics is used to erase memories of, e.g., brutal interrogations of prisoners of war.

The issue of appropriate moral reaction has also been inherited from other MMTs in the case of optogenetic interventions involving the reversible erasure of memories. Here, however, the issue might also take on a somewhat different and possibly even more problematic shape. If a person were to be deprived of the declarative knowledge of a given memory, the expression of an appropriate moral reaction would arguably be impossible. Such a lack of an appropriate moral and emotional reaction might seem heartless and inhuman from the perspective of the surrounding community. Alternatively, a person whose memory valence had been changed would still possess this memory, and could thus plausibly fake an appropriate moral reaction (as psychopaths do); this also raises serious ethical concerns.

The issue of authenticity is also relevant in the case of the memory-modifying potential of optogenetics. Changes in the valences, as well as the complete removal, of memories may cause changes in a person's evaluative schema, especially since such interventions would likely be especially frequent in cases of highly emotional-such as self-defining (traumatic) - memories; thus, being "truthful" to oneself, understood as living according to one's values, may prove problematic in such scenarios. In this context, it is worth considering the moral dilemma faced by the soldier-murderer discussed above if his memories were to be erased by means of optogenetics. Such an individual might not only lack the appropriate moral reactions (as in the case 
of modifying the valence of a memory), but might even be unaware that he had been a killer.

What should be clear, given the above considerations, is that the potential of optogenetics to modify memories generates many more questions than answers. However, as many optogenetic interventions are designed for therapeutic purposes and as the first human clinical trials using optogenetics are already underway, we argue that the neuroethical community must start to consider the ethical challenges associated with the vast capabilities of optogenetics. In this review article, we focused on the memory-modifying potential of optogenetics. However, optogenetics is not restricted to this area, and notable achievements have also been made in other fields of optogenetic research. Thus, we encourage neuroethicists to begin to address potential ethical concerns that may arise in these other neuromodulatory contexts. Although it will probably take some years before scientists find solutions to the current technical and safety problems of optogenetics, and while some time is likely to pass before optogenetics, or optogenetic-like technology (for now, the refined DBS system appears to be the most likely candidate; see $[19,92])$, is approved as a form of treatment for a broader spectrum of brain disorders, it is the role of neuroethicists to anticipate the more universal ethical challenges that optogenetics will eventually have to face.

Open Access This article is licensed under a Creative Commons Attribution 4.0 International License, which permits use, sharing, adaptation, distribution and reproduction in any medium or format, as long as you give appropriate credit to the original author(s) and the source, provide a link to the Creative Commons licence, and indicate if changes were made. The images or other third party material in this article are included in the article's Creative Commons licence, unless indicated otherwise in a credit line to the material. If material is not included in the article's Creative Commons licence and your intended use is not permitted by statutory regulation or exceeds the permitted use, you will need to obtain permission directly from the copyright holder. To view a copy of this licence, visit http://creativecommons.org/licenses/by/4.0/.

\section{References}

1. Deisseroth K (2011) Optogenetics. Nat Methods 8(1):2629. https://doi.org/10.1038/nmeth.f.324

2. Yizhar O, Fenno LE, Davidson TJ, Mogri M, Deisseroth K (2011) Optogenetics in neural systems. Neuron 71(1):934. https://doi.org/10.1016/j.neuron.2011.06.004
3. Packer AM, Roska B, Häusser M (2013) Targeting neurons and photons for optogenetics. Nat Neurosci 16(7):805815. https://doi.org/10.1038/nn.3427

4. Simunovic MP, Shen W, Lin JY, Protti DA, Lisowski L, Gillies MC (2019) Optogenetic approaches to vision restoration. Exp Eye Res 178:15-26. https://doi.org/10.1016/j. exer.2018.09.003

5. Park E, Lee K-S (2019) A new approach to urinary bladder control with optogenetics. Investig Clin Urol 60(2):61-63. https://doi.org/10.4111/icu.2019.60.2.61

6. El-Shamayleh Y, Horwitz GD (2019) Primate optogenetics: progress and prognosis. Proc Natl Acad Sci U S A 116(52):26195-26203. https://doi.org/10.1073 /pnas.1902284116

7. Barnett SC, Perry BAL, Dalrymple-Alford JC, ParrBrownlie LC (2018) Optogenetic stimulation: understanding memory and treating deficits. Hippocampus 28(7): 457-470. https://doi.org/10.1002/hipo.22960

8. Cheng Z, Cui R, Ge T, Yang W, Li B (2020) Optogenetics: what it has uncovered in potential pathways of depression. Pharmacol Res 152:104596. https://doi.org/10.1016/j. phrs.2019.104596

9. Delbeke J, Hoffman L, Mols K, Braeken D, Prodanov D (2017) And then there was light: perspectives of optogenetics for deep brain stimulation and neuromodulation. Front Neurosci 11. https://doi. org/10.3389/fnins.2017.00663

10. Fan Z, Wu B, Wu G, Yao J, Li X, Hu K, Zhou Z, Sui J (2019) Optogenetic inhibition of ventral hippocampal neurons alleviates associative motor learning dysfunction in a rodent model of schizophrenia. PLoS One 14(12): e0227200. https://doi.org/10.1371/journal.pone.0227200

11. Jarrin S, Finn DP (2019) Optogenetics and its application in pain and anxiety research. Neurosci Biobehav Rev 105: 200-211. https://doi.org/10.1016/j.neubiorev.2019.08.007

12. Lux V, Masseck OA, Herlitze S, Sauvage MM (2015) Optogenetic destabilization of the memory trace in CA1: insights into reconsolidation and retrieval processes. Cereb Cortex bhv282. https://doi.org/10.1093/cercor/bhv282

13. Peled A (2011) Optogenetic neuronal control in schizophrenia. Med Hypotheses 76(6):914-921. https://doi. org/10.1016/j.mehy.2011.03.009

14. Rossi MA, Calakos N, Yin HH (2015) Spotlight on movement disorders: what optogenetics has to offer: optogenetics in movement disorders. Mov Disord 30(5): 624-631. https://doi.org/10.1002/mds.26184

15. Mancuso J, Chen Y, Zhao Z, Li X, Xue Z, Wong ST (2013) Optogenetic stimulation of cholinergic projection neurons as an alternative for deep brain stimulation for Alzheimer's treatment. SPIE BiOS. International Society for Optics and Photonics, p 85655M. https://doi.org/10.1117/12.2004379

16. Hemm S, Wårdell K (2010) Stereotactic implantation of deep brain stimulation electrodes: a review of technical systems, methods and emerging tools. Med Biol Eng Comput 48(7):611-624. https://doi.org/10.1007/s11517010-0633-y

17. Herrington TM, Cheng JJ, Eskandar EN (2016) Mechanisms of deep brain stimulation. J Neurophysiol 20

18. Lozano AM, Lipsman N, Bergman H, Brown P, Chabardes S, Chang JW, Matthews K, McIntyre CC, Schlaepfer TE, Schulder M, Temel Y, Volkmann J, Krauss JK (2019) 
Deep brain stimulation: current challenges and future directions. Nat Rev Neurol 15(3):148-160. https://doi. org/10.1038/s41582-018-0128-2

19. Creed M, Pascoli VJ, Lüscher C (2015) Refining deep brain stimulation to emulate optogenetic treatment of synaptic pathology. Science 347(6222):659-664. https://doi. org/10.1126/science.1260776

20. Chen S, Weitemier AZ, Zeng X, He L, Wang X, Tao Y, Huang AJY, Hashimotodani Y, Kano M, Iwasaki H, Parajuli LK, Okabe S, Teh DBL, All AH, Tsutsui-Kimura I, Tanaka KF, Liu X, McHugh TJ (2018) Near-infrared deep brain stimulation via upconversion nanoparticlemediated optogenetics. Science 6

21. Brewer CD, Nicolai E (2014) Reassessing the ethical importance of efficacy and autonomy in optogenetics trials. AJOB Neurosci 5(3):14-16. https://doi.org/10.1080 $/ 21507740.2014 .911219$

22. Gilbert F, Harris AR, Kapsa RMI (2012) Efficacy testing as a primary purpose of phase 1 clinical trials: is it applicable to first-in-human bionics and optogenetics trials? AJOB Neurosci 3(2):20-22. https://doi.org/10.1080 $/ 21507740.2012 .666323$

23. Gilbert F, Harris AR, Kapsa RMI (2014) Controlling brain cells with light: ethical considerations for optogenetic clinical trials. AJOB Neurosci 5(3):3-11. https://doi. org/10.1080/21507740.2014.911213

24. Müller O, Rotter S (2017) Neurotechnology: current developments and ethical issues. Front Syst Neurosci 11. https://doi.org/10.3389/fnsys.2017.00093

25. Müller S, Walter H (2014) Neither speculative nor narrowminded ethics is needed for optogenetics-based DBS in psychiatry and neurology. AJOB Neurosci 5(3):12-14. https://doi.org/10.1080/21507740.2014.911780

26. Howell B, McIntyre CC (2017) Role of soft-tissue heterogeneity in computational models of deep brain stimulation. Brain Stimul 10(1):46-50. https://doi.org/10.1016/j. brs.2016.09.001

27. van Duuren E, van der Plasse G, van der Blom R, Joosten RNJMA, Mulder AB, Pennartz CMA, Feenstra MGP (2007) Pharmacological manipulation of neuronal ensemble activity by reverse microdialysis in freely moving rats: a comparative study of the effects of tetrodotoxin, lidocaine, and muscimol. J Pharmacol Exp Ther 323(1):61-69. https://doi.org/10.1124/jpet.107.124784

28. Kim CK, Adhikari A, Deisseroth K (2017) Integration of optogenetics with complementary methodologies in systems neuroscience. Nat Rev Neurosci 18(4):222-235. https://doi.org/10.1038/nrn.2017.15

29. Ramirez S, Liu X, Lin P-A, Suh J, Pignatelli M, Redondo RL, Ryan TJ, Tonegawa S (2013) Creating a false memory in the Hippocampus. Science 341(6144):387-391. https://doi.org/10.1126/science.1239073

30. Oishi N, Nomoto M, Ohkawa N, Saitoh Y, Sano Y, Tsujimura S, Nishizono H, Matsuo M, Muramatsu S, Inokuchi K (2019) Artificial association of memory events by optogenetic stimulation of hippocampal CA3 cell ensembles. Mol Brain 12(1):2. https://doi.org/10.1186 /s13041-018-0424-1

31. Loftus EF, Pickrell JE (1995) The formation of false memories. Psychiatr Ann 25(12):720-725. https://doi. org/10.3928/0048-5713-19951201-07
32. Crook LS, McEwen LE (2019) Deconstructing the lost in the mall study. Journal of Child Custody 16(1):7-19. https://doi.org/10.1080/15379418.2019.1601603

33. Pezdek K, Hodge D (1999) Planting false childhood memories in children: the role of event plausibility. Child Dev 70(4):887-895. https://doi.org/10.1111/1467-8624.00064

34. Callaghan BL, Li S, Richardson R (2014) The elusive engram: what can infantile amnesia tell us about memory? Trends Neurosci 37(1):47-53. https://doi.org/10.1016/j. tins.2013.10.007

35. Guskjolen A, Kenney JW, de la Parra J, Yeung BA, Josselyn SA, Frankland PW (2018) Recovery of "lost" infant memories in mice. Curr Biol 28(14):2283-2290.e3. https://doi.org/10.1016/j.cub.2018.05.059

36. Roy DS, Muralidhar S, Smith LM, Tonegawa S (2017) Silent memory engrams as the basis for retrograde amnesia. Proc Natl Acad Sci 114(46):E9972-E9979. https://doi. org/10.1073/pnas.1714248114

37. Ryan TJ, Roy DS, Pignatelli M, Arons A, Tonegawa S (2015) Engram cells retain memory under retrograde amnesia. Science 348(6238):1007-10013

38. Nabavi S, Fox R, Proulx CD, Lin JY, Tsien RY, Malinow R (2014) Engineering a memory with LTD and LTP. Nature 511(7509):348-352. https://doi.org/10.1038 /nature13294

39. Goshen I, Brodsky M, Prakash R, Wallace J, Gradinaru V, Ramakrishnan C, Deisseroth K (2011) Dynamics of retrieval strategies for remote memories. Cell 147(3):678689. https://doi.org/10.1016/j.cell.2011.09.033

40. Nader K, Schafe GE, Le Doux JE (2000) Fear memories require protein synthesis in the amygdala for reconsolidation after retrieval. Nature 406(6797):722726. https://doi.org/10.1038/35021052

41. Redondo RL, Kim J, Arons AL, Ramirez S, Liu X, Tonegawa S (2014) Bidirectional switch of the valence associated with a hippocampal contextual memory engram. Nature 513(7518):426-430. https://doi.org/10.1038 /nature13725

42. Cahill L, Prins B, Weber M, McGaugh JL (1994) Betaadrenergic activation and memory for emotional events. Nature 371(6499):702-704. https://doi.org/10.1038 $1371702 \mathrm{a} 0$

43. Dudai Y, Karni A, Born J (2015) The consolidation and transformation of memory. Neuron 88(1):20-32. https://doi.org/10.1016/j.neuron.2015.09.004

44. Huff ML, Miller RL, Deisseroth K, Moorman DE, LaLumiere RT (2013) Posttraining optogenetic manipulations of basolateral amygdala activity modulate consolidation of inhibitory avoidance memory in rats. Proc Natl Acad Sci 110(9):3597-3602. https://doi.org/10.1073 /pnas.1219593110

45. Wolf OT (2008) The influence of stress hormones on emotional memory: relevance for psychopathology. Acta Psychol 127(3):513-531. https://doi.org/10.1016/j. actpsy.2007.08.002

46. Cahill L (2003) Enhanced human memory consolidation with post-learning stress: interaction with the degree of arousal at encoding. Learn Mem 10(4):270-274. https://doi.org/10.1101/lm.62403

47. Sandrini M, Cohen LG, Censor N (2015) Modulating reconsolidation: a link to causal systems-level dynamics 
of human memories. Trends Cogn Sci 19(8):475-482. https://doi.org/10.1016/j.tics.2015.06.002

48. Wood NE, Rosasco ML, Suris AM, Spring JD, Marin MF, Lasko NB, Goetz JM, Fischer AM, Orr SP, Pitman RK (2015) Pharmacological blockade of memory reconsolidation in posttraumatic stress disorder: three negative psychophysiological studies. Psychiatry Res 225(12):31-39. https://doi.org/10.1016/j.psychres.2014.09.005

49. Chalkia A, Weermeijer J, Van Oudenhove L, Beckers T (2019) Acute but not permanent effects of propranolol on fear memory expression in humans. Front Hum Neurosci 13. https://doi.org/10.3389/fnhum.2019.00051

50. Brunet A, Saumier D, Liu A, Streiner DL, Tremblay J, Pitman RK (2018) Reduction of PTSD symptoms with prereactivation propranolol therapy: a randomized controlled trial. Am J Psychiatr 175(5):427-433. https://doi. org/10.1176/appi.ajp.2017.17050481

51. Kindt M, Soeter M, Vervliet B (2009) Beyond extinction: erasing human fear responses and preventing the return of fear. Nat Neurosci 12(3):256-258. https://doi.org/10.1038 /nn.2271

52. Soeter M, Kindt M (2015) An abrupt transformation of phobic behavior after a post-retrieval amnesic agent. Biol Psychiatry 78(12):880-886. https://doi.org/10.1016/j. biopsych.2015.04.006

53. Elsey J, Kindt M (2016) Manipulating human memory through reconsolidation: ethical implications of a new therapeutic approach. AJOB Neurosci 7(4):225-236. https://doi.org/10.1080/21507740.2016.1218377

54. Phelps EA, Hofmann SG (2019) Memory editing from science fiction to clinical practice. Nature 572(7767):4350. https://doi.org/10.1038/s41586-019-1433-7

55. Misanin JR, Miller RR, Lewis DJ (1968) Retrograde amnesia produced by electroconvulsive shock after reactivation of a consolidated memory trace. Science, New Series 160(3827):554-555

56. Schiller D, Monfils M-H, Raio CM, Johnson DC, LeDoux JE, Phelps EA (2010) Preventing the return of fear in humans using reconsolidation update mechanisms. Nature 463(7277):49-53. https://doi.org/10.1038/nature08637

57. Schiller D, Phelps EA (2011) Does reconsolidation occur in humans? Front Behav Neurosci 5. https://doi. org/10.3389/fnbeh.2011.00024

58. Bouton ME, Nelson JB (1998) The role of context in classical conditioning: some implications for cognitive behavior therapy. In: O'Donohue WT (ed) Learning and behavior therapy. Allyn \& Bacon, Needham Heights, pp 59-84

59. Vansteenwegen D, Hermans D, Vervliet B, Francken G, Beckers T, Baeyens F, Eelen P (2005) Return of fear in a human differential conditioning paradigm caused by a return to the original acquistion context. Behav Res Ther 43: 323-336. https://doi.org/10.1016/j.brat.2004.01.001

60. Ramirez S, Liu X, MacDonald CJ, Moffa A, Zhou J, Redondo RL, Tonegawa S (2015) Activating positive memory engrams suppresses depression-like behaviour. Nature 522(7556):335-339. https://doi.org/10.1038 /nature 14514

61. Dresler M, Sandberg A, Bublitz C, Ohla K, Trenado C, Mroczko-Wąsowicz A, Kühn S, Repantis D (2019) Hacking the brain: dimensions of cognitive enhancement.
ACS Chem Neurosci 10(3):1137-1148. https://doi. org/10.1021/acschemneuro.8b00571

62. Suthana N, Fried I (2014) Deep brain stimulation for enhancement of learning and memory. NeuroImage 85:9961002. https://doi.org/10.1016/j.neuroimage.2013.07.066

63. Aldehri M, Temel Y, Alnaami I, Jahanshahi A, Hescham S (2018) Deep brain stimulation for Alzheimer's disease: an update. Surg Neurol Int 9(1):58. https://doi.org/10.4103 /sni.sni_342_17

64. Fenster RJ, Lebois LAM, Ressler KJ, Suh J (2018) Brain circuit dysfunction in post-traumatic stress disorder: from mouse to man. Nat Rev Neurosci 19(9):535-551. https://doi.org/10.1038/s41583-018-0039-7

65. Gittis AH, Yttri EA (2018) Translating insights from optogenetics into therapies for Parkinson's disease. Curr Opin Biomed Eng 8:14-19. https://doi.org/10.1016/j. cobme.2018.08.008

66. Fanselow MS, Poulos AM (2005) The neuroscience of mammalian associative learning. Annu Rev Psychol 56(1):207-234. https://doi.org/10.1146/annurev. psych.56.091103.070213

67. Rajkowska G, Miguel-Hidalgo JJ, Wei J, Dilley G, Pittman SD, Meltzer HY, Overholser JC, Roth BL, Stockmeier CA (1999) Morphometric evidence for neuronal and glial prefrontal cell pathology in major depression. Biol Psychiatry 45(9):1085-1098. https://doi.org/10.1016/s0006-3223(99 $00041-4$

68. Zhou Q, Homma KJ, Poo M (2004) Shrinkage of dendritic spines associated with long-term depression of hippocampal synapses. Neuron 44(5):749-757. https://doi. org/10.1016/j.neuron.2004.11.011

69. Choi GB, Stettler DD, Kallman BR, Bhaskar ST, Fleischmann A, Axel R (2011) Driving opposing behaviors with ensembles of Piriform neurons. Cell 146(6): 1004-1015. https://doi.org/10.1016/j.cell.2011.07.041

70. Deisseroth K (2015) Optogenetics: 10 years of microbial opsins in neuroscience. Nat Neurosci 18(9):1213-1225. https://doi.org/10.1038/nn.4091

71. Branca MA (2005) Gene therapy: cursed or inching towards credibility? Nat Biotechnol 23(5):519-521. https://doi.org/10.1038/nbt0505-519

72. Blessing D, Déglon N (2016) Adeno-associated virus and lentivirus vectors: a refined toolkit for the central nervous system. Curr Opin Virol 21:61-66. https://doi.org/10.1016 /j.coviro.2016.08.004

73. Ginn SL, Amaya AK, Alexander IE, Edelstein M, Abedi MR (2018) Gene therapy clinical trials worldwide to 2017: an update. J Gene Med 20(5):e3015. https://doi. org/10.1002/jgm.3015

74. Sehara Y, Fujimoto K, Ikeguchi K, Katakai Y, Ono F, Takino N, Ito M, Ozawa K, Muramatsu S (2017) Persistent expression of dopamine-synthesizing enzymes 15 years after gene transfer in a primate model of Parkinson's disease. Hum Gene Ther Clin Dev 28(2):74 79. https://doi.org/10.1089/humc.2017.010

75. Edward ES, Kouzani AZ, Tye SJ (2018) Towards miniaturized closed-loop optogenetic stimulation devices. J Neural Eng 15(2):021002. https://doi.org/10.1088/17412552/aa7d62

76. Park SI, Shin G, Banks A, McCall JG, Siuda ER, Schmidt MJ, Chung HU, Noh KN, Mun JG-H, Rhodes J, Bruchas 
MR, Rogers JA (2015) Ultraminiaturized photovoltaic and radio frequency powered optoelectronic systems for wireless optogenetics. J Neural Eng 12(5):056002. https://doi. org/10.1088/1741-2560/12/5/056002

77. Repina NA, McClave T, Bao X, Kane RS, Schaffer DV (2019). Engineered illumination devices for optogenetic control of cellular signaling dynamics. BioRxiv. https://doi.org/10.1101/675892

78. Shema R, Haramati S, Ron S, Hazvi S, Chen A, Sacktor TC, Dudai Y (2011) Enhancement of consolidated longterm memory by overexpression of protein kinase $\mathrm{M}$ in the Neocortex. Science 331(6021):1207-1210. https://doi. org/10.1126/science.1200215

79. Wei F, Wang G-D, Kerchner GA, Kim SJ, Xu H-M, Chen Z-F, Zhuo M (2001) Genetic enhancement of inflammatory pain by forebrain NR2B overexpression. Nat Neurosci 4(2):164-169. https://doi.org/10.1038/83993

80. de Haan S, Rietveld E, Stokhof M, Denys D (2015) Effects of deep brain stimulation on the lived experience of obsessive-compulsive disorder patients: in-depth interviews with 18 patients. PLoS One 10(8):e0135524. https://doi.org/10.1371/journal.pone.0135524

81. Eich S, Müller O, Schulze-Bonhage A (2019) Changes in self-perception in patients treated with neurostimulating devices. Epilepsy Behav 90:25-30. https://doi. org/10.1016/j.yebeh.2018.10.012

82. Liddle J, Phillips J, Gustafsson L, Silburn P (2018) Understanding the lived experiences of Parkinson's disease and deep brain stimulation (DBS) through occupational changes. Aust Occup Ther J 65(1):45-53. https://doi. org/10.1111/1440-1630.12437

83. Mathers J, Rick C, Jenkinson C, Garside R, Pall H, Mitchell R, Bayliss S, Jones LL (2016) Patients' experiences of deep brain stimulation for Parkinson's disease: a qualitative systematic review and synthesis. BMJ Open 6(6):e011525. https://doi.org/10.1136/bmjopen-2016011525

84. Thomson CJ, Segrave RA, Carter A (2019) Changes in personality associated with deep brain stimulation: a qualitative evaluation of clinician perspectives. Neuroethics. https://doi.org/10.1007/s12152-019-09419-2

85. Aggleton JP (2014) Looking beyond the hippocampus: old and new neurological targets for understanding memory disorders. Proc R Soc B Biol Sci 281(1786):20140565. https://doi.org/10.1098/rspb.2014.0565

86. Hamann S (2001) Cognitive and neural mechanisms of emotional memory. Trends Cogn Sci 5(9):394-400. https://doi.org/10.1016/S1364-6613(00)01707-1

87. Milad MR, Quirk GJ (2002) Neurons in medial prefrontal cortex signal memory for fear extinction. Nature 420(6911):70-74. https://doi.org/10.1038/nature01138

88. De Brigard F (2014) Is memory for remembering? Recollection as a form of episodic hypothetical thinking. Synthese 191(2):155-185. https://doi.org/10.1007 /s11229-013-0247-7

89. Schechter E (2018) Self-consciousness and 'split' brains: the minds' I. Oxford University Press, Oxford

90. Stefanik MT, Moussawi K, Kupchik YM, Smith KC, Miller RL, Huff ML, Deisseroth K, Kalivas PW, LaLumiere RT (2013) Optogenetic inhibition of cocaine seeking in rats: Optogenetic inhibition of cocaine seeking in rats. Addict Biol 18(1):50-53. https://doi.org/10.1111 /j.1369-1600.2012.00479.x

91. Walker MC, Kullmann DM (2020) Optogenetic and chemogenetic therapies for epilepsy. Neuropharmacology 168:107751. https://doi.org/10.1016/j. neuropharm.2019.107751

92. Lüscher C, Pollak P (2016) Optogenetically inspired deep brain stimulation: linking basic with clinical research. Swiss Med Wkly 146:w14278. https://doi.org/10.4414 /smw.2016.14278

93. Gilbert F, Goddard E (2014) Thinking ahead too much: speculative ethics and implantable brain devices. AJOB Neurosci 5(1):49-51. https://doi.org/10.1080 $/ 21507740.2013 .863252$

94. Johansson V, Garwicz M, Kanje M, Halldenius L, Schouenborg J (2014) Thinking ahead on deep brain stimulation: an analysis of the ethical implications of a developing technology. AJOB Neurosci 5(1):24-33. https://doi. org $/ 10.1080 / 21507740.2013 .863243$

95. McAdams DP, Jones BK (2017) Making meaning in the wake of trauma: resilience and redemption. In: Altmaier EM (ed) Reconstructing meaning after trauma. Theory, research, and practice. Elsevier, London, pp 3-16. https://doi.org/10.1016/B978-0-12-803015-8.00001-2

96. Tedeschi RG, Calhoun LG (2004) Posttraumatic growth: conceptual foundations and empirical evidence. Psychol Inq 15(1):1-18 JSTOR

97. Liao SM, Sandberg A (2008) The normativity of memory modification. Neuroethics 1(2):85-99. https://doi. org/10.1007/s12152-008-9009-5

98. Liao SM, Wasserman DT (2007) Neuroethical concerns about moderating traumatic memories. Am J Bioeth 7(9): 38-40. https://doi.org/10.1080/15265160701518623

99. Erler A (2011) Does memory modification threaten our authenticity? Neuroethics 4(3):235-249. https://doi. org/10.1007/s12152-010-9090-4

100. Strawson P (1962) Freedom and resentment. Proceedings of the British Academy, volume 48, pp 1-25. Reprinted in Strawson P (1974) Freedom and Resentment and Other Essays, Methuen

101. Kass L (2003) Beyond therapy: biotechnology and the pursuit of human improvement. President's Council on Bioethics, Washington, DC

102. Nyholm S, O’Neill E (2016) Deep brain stimulation, continuity over time, and the true self. Camb Q Healthc Ethics 25(04):647-658. https://doi.org/10.1017 /S0963180116000372

103. Sartre J-P (1992) Being and nothingness. Simon and Schuster

104. Pugh J, Maslen H, Savulescu J (2017) Deep brain stimulation, authenticity and value. Camb Q Healthc Ethics 26(4): 640-657. https://doi.org/10.1017/S0963180117000147

105. Lavazza A (2018) Memory-modulation: self-improvement or self-depletion? Front Psychol 9. https://doi.org/10.3389 /fpsyg.2018.00469

106. Hui K, Fisher CE (2015) The ethics of molecular memory modification. J Med Ethics 41(7):515-520. https://doi. org/10.1136/medethics-2013-101891

107. Wilson JP (2007) The posttraumatic self: restoring meaning and wholeness to personality. Routledge 
108. Greenberg DM, Baron-Cohen S, Rosenberg N, Fonagy P, Rentfrow PJ (2018) Elevated empathy in adults following childhood trauma. PLoS One 13(10):e0203886. https://doi. org/10.1371/journal.pone.0203886

109. Lavazza A (2015) Erasing traumatic memories: when context and social interests can outweigh personal autonomy. Philos Ethics Humanit Med 10(1):3. https://doi. org/10.1186/s13010-014-0021-6

110. Glannon W (2011) Brain, body, and mind: neuroethics with a human face. Oxford University Press, Oxford

111. Lavazza A (2016) What we may forget when discussing human memory manipulation. AJOB Neurosci 7(4):249251. https://doi.org/10.1080/21507740.2016.1251988

112. Lavazza A (2019) Moral bioenhancement through memory-editing: a risk for identity and authenticity? Topoi 38(1): 15-27. https://doi.org/10.1007/s1 1245-017-9465-9

113. Christman J (2018) Autonomy in moral and political philosophy. In: Zalta EN (ed) The Stanford encyclopedia of philosophy (Spring 2018). Metaphysics Research Lab, Stanford University. https://plato.stanford. edu/archives/spr2018/entries/autonomy-moral/. Accessed 26 Sep 2020

114. Kolber AJ (2006) Therapeutic forgetting: the legal and ethical implications of memory dampening (SSRN Scholarly Paper ID 887061). Social Science Research Network. https://papers.ssrn.com/abstract $=887061$. Accessed 15 Oct 2020

115. Mill JS (1865) On liberty. Longmans, Green, and Company, London

116. Levy N (2007) Neuroethics: challenges for the 21st century. Cambridge University Press, Cambridge. https://doi. org/10.1017/CBO9780511811890

117. Cabrera LY, Elger BS (2016) Memory interventions in the criminal justice system: some practical ethical considerations. J Bioeth Inq 13(1):95-103. https://doi. org/10.1007/s11673-015-9680-2

118. Singer JA, Blagov P (2004) The integrative function of narrative processing: autobiographical memory, selfdefining memories, and the life story of identity. In: Beike RD, Lampinen JM, Behrend DA (eds) The self and memory. Psychology Press, New York, pp 117-138

119. Singer JA, Blagov P, Berry M, Oost KM (2013) Selfdefining memories, scripts, and the life story: narrative identity in personality and psychotherapy: healthy narrative identity. J Pers 81(6):569-582. https://doi.org/10.1111 /jopy.12005

120. Schechtman M (1996) The constitution of selves. Cornell University Press, Ithaca

121. Schechtman M (2010) Philosophical reflections on narrative and deep brain stimulation. J Clin Ethics 21(2):133139

122. Baylis F (2013) "I am who I am": on the perceived threats to personal identity from deep brain stimulation. Neuroethics 6(3):513-526. https://doi.org/10.1007 /s12152-011-9137-1

123. Gilbert F, Goddard E, Viaña JNM, Carter A, Horne M (2017) I miss being me: phenomenological effects of deep brain stimulation. AJOB Neurosci 8(2):96-109. https://doi. org/10.1080/21507740.2017.1320319

124. Schüpbach M, Gargiulo M, Welter ML, Mallet L, Béhar C, Houeto JL, Maltête D, Mesnage V, Agid Y (2006) Neurosurgery in Parkinson disease: a distressed mind in a repaired body? Neurology 66(12):1811-1816. https://doi. org/10.1212/01.wnl.0000234880.51322.16

Publisher's Note Springer Nature remains neutral with regard to jurisdictional claims in published maps and institutional affiliations. 